\title{
Pengaruh Interaksi Sosial Komunitas Adat Baduy Luar Terhadap Persepsinya pada Kebutuhan Keluarga
}

\author{
Ahmad Sihabudin ${ }^{1}$, Basita Ginting S, Djoko Susanto, Pang S Asngari \\ ${ }^{1}$ Universitas Tirtayasa Banten \\ ${ }^{2}$ Departemen Sains Komunikasi dan Pengembangan Masyarakat, \\ Fakultas Ekologi Manusia, Institut Pertanian Bogor \\ ${ }^{3}$ Pusat Penelitian Gizi Departemen Kesehatan
}

\begin{abstract}
The objectives of this study are (1) to get description the family needs of the Outer Baduy Community, (2) to analyze factors that influence the perception of Outer Baduy Community towards the needs of their families; and (3) To get tentative model of Planned Changes, such as intervention, and things that need to be intervened to fulfill the needs of Outer Baduy Community's Family. (4) Social Interaction through interpersonal communication and with the agent of change had significant relation to the perception of Heads of family on basic needs, safety, loved, and appreciated are felt, and the perception towards the satisfaction on safety, loved, and appreciated; To develop strategy and policy in fulfilling the needs of SCC family of Baduy can be created through the enhancement of standard family's needs by making a centre of business practice, discussion forum (community information group), escalation of business facility, community participation, the support by opinion leader in Baduy community, private support, and the motive and the awareness to change is high.
\end{abstract}

Key words: community of baduy custom, perception, fulfillment of family needs.

\section{Pendahuluan}

Salah satu masyarakat yang perlu mendapatkan perhatian khusus adalah Komunitas Adat Terpencil (KAT). Komunitas ini bermukim di berbagai pelosok wilayah. Data menginformasikan kepada kita bahwa KAT terdapat hampir di seluruh wilayah Nusantara, mulai dari Sabang di Provinsi Nanggroe Aceh Darussalam (NAD) hingga Merauke di Provinsi Papua kita menemukan keberadaan KAT. Penelitian ini mengkaji salah satu KAT yaitu suku Baduy Luar. Secara administratif wilayah Baduy atau biasa pula disebut wilayah "Rawayan" atau wilayah "Kanekes" termasuk dalam Desa Kanekes, Kecamatan Leuwidamar, Kabupaten Lebak, Provinsi Banten (dulu masuk wilayah Jawa Barat). Wilayah yang dihuni orang Baduy berada pada kawasan Pegunungan Kendeng yang sebagian merupakan hutan lindung.

Masyarakat Baduy adalah salah satu etnik yang dapat dikatakan sebagai komunitas yang masih memegang tradisi dan cenderung tertutup, atau dalam istilah sekarang Komunitas Adat Terpencil sebagai pengganti istilah Masyarakat Terasing.

Pasal 2 Keppres No. 111/1999 tentang pembinaan kesejahteraan sosial komunitas adat terpencil diamanatkan: "Pembinaan kesejahteraan sosial komunitas adat terpencil bertujuan untuk memberdayakan komunitas adat terpencil dalam segala aspek kehidupan dan penghidupan agar mereka dapat hidup secara wajar baik jasmani, rohani, dan sosial sehingga dapat berperan aktif dalam pembangunan, yang pelaksanaannya dilakukan dengan memperhatikan adat istiadat setempat."

Misi pemberdayaan komunitas adat terpencil adalah: meningkatkan harkat dan martabat komunitas adat terpencil, meningkatkan kualitas hidup komunitas adat terpencil, memperkuat

\footnotetext{
${ }^{1}$ Korespondensi penulis: 081218310785

E-mail: sihab_tea@yahoo.co.id
} 
pranata dalam jaringan sosial, mengembangkan sistem kehidupan dan penghidupan yang berlaku pada komunitas adat terpencil, dan meningkatkan peranserta dan tanggung jawab sosial masyarakat dalam proses pemberdayaan Komunitas Adat Terpencil. KAT yang kini berjumlah sekitar 1,1 juta jiwa bukan jumlah yang sedikit. KAT masih terisolasi, miskin, dan lemah (Abdullah, 2004). Masyarakat Baduy berjumlah 10.941 orang, yang terdiri dari 5.500 pria, dan 5.441wanita, adapun jumlah KK 2.726 orang.

Terdapat beberapa gejala yang menjadi fokus penelitian ini, yaitu masalah filosofis sistem nilai yang dianut oleh komunitas Baduy dan masalah bagaimana mereka memberi arti atau nilai terhadap usaha pemenuhan kebutuhan keluarga bagi komunitas Baduy Luar.

Tujuan penelitian ini adalah: (1) Memperoleh gambaran persepsi kebutuhan keluarga masyarakat Baduy Luar. (2) Mengkaji faktor-faktor yang mempengaruhi persepsi masyarakat Baduy Luar terhadap kebutuhan keluarganya. (3) Mendapatkan suatu model perubahan terencana, macam intervensi, dan hal-hal yang perlu di intervensi untuk memenuhi kebutuhan keluarga Komunitas Adat Baduy Luar.

\section{Komunitas Adat Terpencil Baduy}

Menurut Adimihardja (2007) komunitas adat sebagai bagian dari masyarakat Indonesia adalah kelompok masyarakat yang terisolasi, baik secara fisik, geografi, maupun sosial budaya. Sebagian besar komunitas ini bertempat tinggal di daerah terpencil dan sulit dijangkau. Pranata sosial dalam komunitas adat ini umumnya bertumpu pada hubungan kekerabatan yang sangat terbatas dan homogen. Kehidupan mereka sehari-hari masih didasarkan pada interaksi tradisional yang bersifat biologis darah dan ikatan tali perkawinan. Abdullah (2004) berpendapat kelompok masyarakat inilah yang dikategorikan sebagai Komunitas Adat yang masih hidup terpencil, keterpencilan itu ada 2 (dua) aspek yaitu secara eksternal: kenapa pihak luar belum atau sulit memberikan akses pelayanan sosial dasar pada mereka. Secara internal: Kenapa mereka belum dan atau sulit mendapatkan akses pelayanan sosial dasar.

Pengertian Komunitas Adat Terpencil (KAT) dalam surat keputusan Presiden No 111 tahun 1999, adalah kelompok sosial budaya yang bersifat lokal dan terpencar serta kurang atau belum terlibat dalam jaringan dan pelayanan baik sosial, ekonomi maupun politik.

Berdasarkan pengertian tersebut, maka kelompok masyarakat tertentu dapat dikategorikan sebagai Komunitas Adat Terpencil jika terdapat ciri-ciri umum yang berlaku universal sebagai berikut: (a) Berbentuk komunitas kecil, tertutup dan homogen. (b) Pranata sosial bertumpu pada hubungan kekerabatan. (c) Pada umumnya lokasinya terpencil secara geografis dan relatif sulit dijangkau. (d) Pada umumnya masih hidup dengan sistem ekonomi sub sisten. (e) Peralatan teknologinya sederhana, sangat tradisionil. (f) Ketergantungan pada lingkungan hidup dan sumber daya alam setempat relatif tinggi. (g) Akses terhadap pelayanan sosial, ekonomi, dan politik tebatas.

Dari uraian tersebut dapat dikatakan bahwa komunitas adat terpencil adalah kelompok masyarakat yang masih terbatas mendapatkan berbagai akses pelayanan dasar sosial yang disebabkan secara geografis sulit dijangkau, dan cenderung sifat masyarakatnya tertutup.

\section{Persepsi}

Orang awam mengatakan persepsi adalah kesan kita terhadap suatu obyek, bisa keadaan, benda, atau suatu peristiwa. Ada beberapa definisi persepi yang dikemukakan oleh para ahli antara lain. Menurut Litterer ( Asngari, 1984), persepsi adalah "the understanding or view people have of things in the world around them," sedangkan Hilgard (Asngari, 1984), menyebutkan bahwa "perception in the process of becoming aware of objection."

Combs, Avila dan Purkey (Asngari, 1984) mendefinisikan persepsi sebagai berikut: "Perception is the interpretation by individuals of how things seem to them, especially in 
reference to how individuals view themselves in relation to the world in which they are involved."

Menurut Rakhmat (2004), persepsi adalah pengalaman tentang obyek, peristiwa, atau hubungan-hubungan yang diperoleh dengan menyimpulkan informasi dan menafsirkan pesan. Menurut Desederato (Rakhmat, 2004), persepsi ialah memberikan makna pada stimuli inderawi (sensory stimuli). Ada hubungan sensasi dengan persepsi, sensasi adalah bagian dari persepsi. Walaupun begitu, menafsirkan makna informasi inderawi tidak hanya melibatkan sensasi tetapi juga atensi, ekspektasi, motivasi dan memori.

Pembentukan persepsi, menurut Litterer, ada tiga mekanisme : selectivity, closure, and interpretation ( Asngari, 1982). Secara skematis, ditunjukkan dalam Gambar 2.

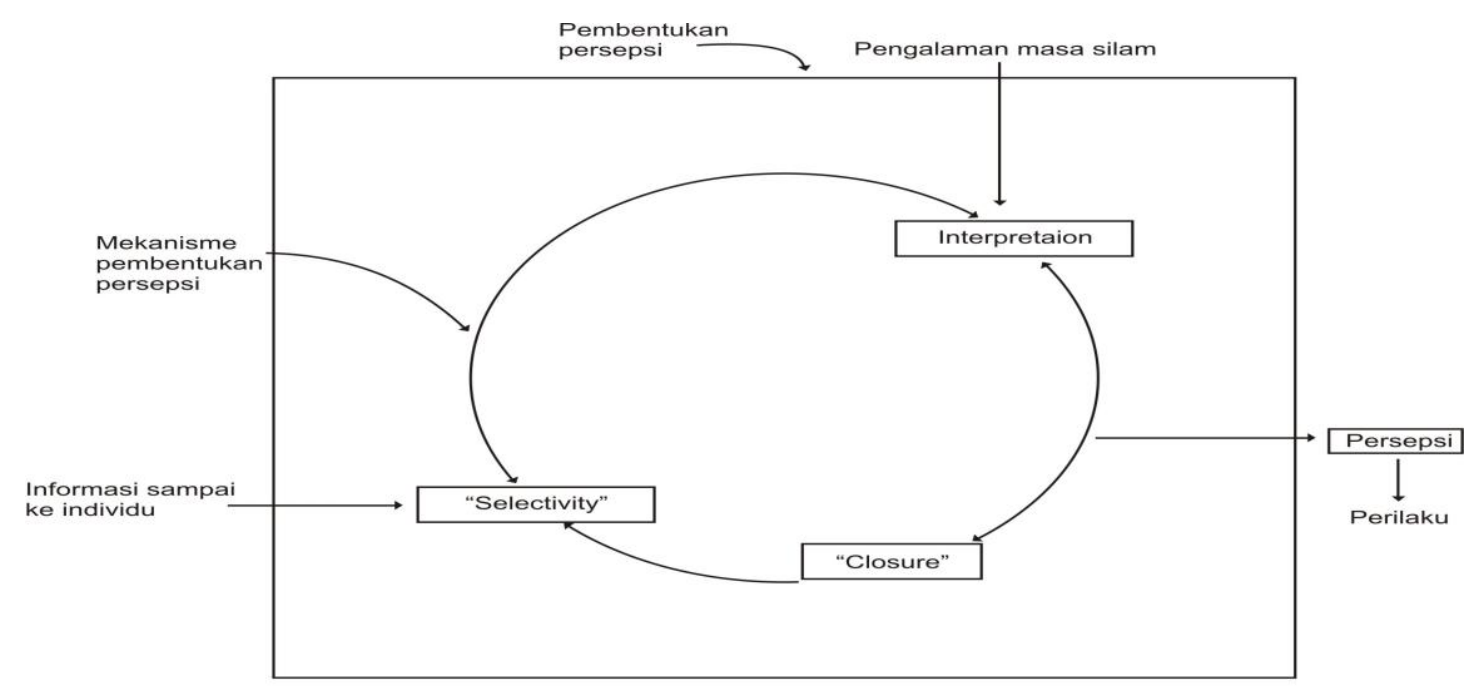

Gambar 2. Pembentukan Persepsi Literer (1973), (Asngari:1984)

Informasi yang sampai kepada seseorang menyebabkan individu yang bersangkutan membentuk persepsi, dimulai dengan pemilihan atau menyaringnya, kemudian informasi yang masuk tersebut disusun menjadi kesatuan yang bermakna, dan akhirnya terjadilah interprestasi mengenai fakta keseluruhan informasi itu. Pada fase interprestasi ini, Pengalaman masa silam dan dahulu memegang peranan yang penting.

\section{Kebutuhan Keluarga}

Manusia yang hidup bermasyarakat membutuhkan hal-hal yang dapat menunjang dan menjalankan proses kehidupan, sedangkan kebutuhannya itu adalah bersifat sejagat artinya, artinya kebutuhan merupakan berbagai hal yang harus dipenuhi manusia untuk dapat melangsungkan kehidupannya dan untuk dapat hidup lebih baik. Menurut Huntington (Garna, 2007) berbagai kebutuhan manusia itu dapat dikategorikan dalam tiga jenis, yaitu: (1) Kebutuhan utama atau primer, kebutuhan yang kemunculannya bersumber pada aspek biologi atau organisma tubuh manusia, seperti makanan dan minuman, perlindungan dari iklim, istirahat, dan kesehatan. (2) Kebutuhan sosial atau kebutuhan skunder, kebutuhan yang terwujud sebagai akibat atau hasil dari usaha memenuhi kebutuhan primer, dan yang harus dipenuhi dengan melibatkan sejumlah orang, seperti berhubungan dengan sesama, kegiatan yang dilakukan bersama, sistem pendidikan, dan keteraturan serta kontrol sosial. (3) Kebutuhan integratif, kebutuhan yang muncul dan terpencar dari hakekat manusia sebagai makhluk berfikir dan bermoral, yang fungsinya menggabungkan berbagai kebutuhan dan perangkat tingkah lakunya menjadi suatu sistem yang bulat serta menyeluruh dan masuk akal bagi para pendukung kebudayaannya, seperti perasaan tentang yang benar dan yang salah, ungkapan persaan bersama, rasa keyakinan diri, rekreasi dan hiburan. 
Dalam memenuhi kebutuhan dan manfaat pada proses kehidupan manusia maka kebudayaan dapat dilihat sebagai keseluruhan pengetahuan yang dimiliki manusia sebagai makhluk sosial, yang terdiri dari perangkat model-model pengetahuan yang secara selektif dapat digunakan untuk memahami dan melakukan interpretasi lingkungan yang dihadapi, dan untuk mendorong serta melaksanakan tindakan yang diperlukan, Spradley (1972) (Garna, 2007).

Menurut Maslow (Alwisol, 2004), semua manusia mempunyai kebutuhan dasar umum yang terdiri atas beberapa tingkatan yakni tingkatan kebutuhan dasar fisik harus terpenuhi lebih dulu atau sekurang-kurangnya sebagian terpenuhi agar kehidupan terus berlanjut. Lebih jauh Maslow berpendapat, bahwa orang akan berusaha keras untuk memenuhi kebutuhannya, karena mempunyai dorongan atau motivasi untuk mencapai potensi setinggi-tingginya.

Konsep hirarki kebutuhan Maslow diartikan sebagai proses atau sistem yang menempatkan materi dan orang menurut derajat pentingnya. Hirarki kebutuhan adalah penempatan persyaratan atau keperluan fungsi manusia berdasarkan derajat (urutan) tingkatan pentingnya. Ia mengembangkan suatu tingkatan atau hirarki kabutuhan manusia terdiri lima kategori, yaitu kebutuhan fisiologi, keselamatan, sosial, harga diri, dan aktualisasi diri.

\section{Interaksi Sosial}

Sebagaimana telah dikemukakan di depan bahwa terbentuknya persepsi, ditentukan oleh faktor fungsional dan faktor strutural. Faktor fungsional berasal dari kebutuhan, pengalaman masa lalu dan hal lain yang termasuk hal-hal apa yang kita sebut sebagai faktor personal, salah satunya adalah interaksi sosialnya. yang menentukan persepsi bukan jenis atau bentuk stimuli tetapi krakteristik orang yang memberikan respon pada stimuli itu. Krech dan Crutchfield (Rakhmat, 2004). Interaksi sosial adalah titik awal berlangsungnya suatu peristiwa sosial. Menurut Gillin dan Gillin (Kolopaking dkk, 2003), interaksi sosial merupakan hubungan antara orang peroangan, antara kelompok-kelompok manusia, maupun antara orang-perorangan dengan kelompok manusia.

Kontak antara orang-perorang menurut Rakhmat (2004) dapat dikatakan sebagai kegiatan komunikasi interpersonal, hubungan beberapa orang yang terjadi diantara mereka dapat dikatakan sebagai komunikasi kelompok, kontak dengan media apakah suratkabar, televisi dan lain-lain dapat dikatakan sebagai proses komunikasi massa. Artinya kontak bisa saja terjadi baik dengan manusia amaupun benda.

Menurut Kolopaking dkk (2003) kontak sosial dapat berlangsung dalam tiga bentuk, yaitu: (a) antara orang perorangan, misalnya antara seorang anak dengan temannya, (b) antara orang perorangan dengan suatu keompok, misalnya antara seorang anak dengan keluarganya, dan (c) antarasuatu kelompok dengan kelompok lainnya, misalnya antara kelompok mahasiswa asal Semarang dengan kelompok mahasiswa asal Malang.

Jadi suatu peristiwa sosial disebut interaksi sosial bila terjadi kontak antara orangperorangan dengan seorang atau kelompok, dan terjadi pertukaran pesan atau melakukan komunikasi. Interaksi tidak selamanya harus dengan orang adakalanya juga berinteraksi dengan benda atau sesuatu. Seperti televisi, siaran radio, surat kabar atau media massa, dan lain-lain.

Dari uraian di atas bila dikaitkan dengan masalah penelitian adalah interaksi Komunitas Baduy Luar yang meliputi interaksinya dengan diantaa sesama mereka, interaksi dengan orang diluar mereka termasuk agen pembaharu, dan interaksi mereka dengan media, atau kegiatan mereka dalam melakukan komunikasi interpersonal, komunikasi kelompok, dan interaksi mereka dengan media.

Dari uraian diatas disusun kerangka berfikir, dan hubungan antar variabel penelitian (Gambar 2), hal -hal yang mempengaruhi persepsi komunitas adat Baduy luar terhadap kebutuhan keluarga adalah: Status sosial ekonomi orang Baduy Luar (X1), Usaha-Usaha (X2), Motif (X3), Interaksi Sosial (X4): (1) interaksi dengan sesama / komunikasi interpersonal, (2) interaksi dengan agen pembaharu, (3) interaksi dengan media; Nilai Sosial Budaya (X5).

Persepsi komunitas adat Baduy yang dirasakan (Y1) dan kepuasannya (Y2) pada kebutuhan dasar (fisiologi), rasa aman, dicintai dan dimiliki, dan penghargaan diri. Keseluruhan peubah-peubah ini diamati dan diteliti, dianalisis, dan dikaji hubungan-hubungan 
dan pengaruhnya serta diinterpretasikan untuk menjawab masalah penelitian dan tujuan penelitian.

\section{Metode Penelitian}

Penelitian ini dilaksanakan di Desa Kanekes, Kecamatan Leuwidamar, Kabupaten Lebak, Provinsi Banten Lokasi Pemukiman Masyarakat Baduy sesuai Perda No. 32 Kabupaten Lebak Tentang Perlindungan Hak Ulayat Masyarakat Baduy, yang berjumlah 58 kampung, yang terdiri dari 3 Kampung termasuk Baduy Dalam yaitu Cibeo, Cikeusik, dan Cikartawana, dan 55 Kampung Baduy Luar. Lamanya penelitian 6 Bulan dan pelaksanaan pengumpulan data dimulai sejak Oktober 2008 sd. Maret 2009.

Dengan pertimbangan perkampungan Baduy cenderung homogen, maka ditetapkan 15 kampung secara acak yang berada di jalur menuju Baduy Dalam, Jalur Handap Kulon" (Bawah Barat); 6 Kampung. Jalur "Teungah Kulon" (Tengah Barat), "Teungah Luhur" (Tengah Atas), jalur ini sebenarnya terusan dari jalur Tengah Barat 8 Kampung, dan Kampung Kaduketug (ibu kota Desa Kanekes / Pusat pemerintahan) sebagai kampung yang paling terluar dari Baduy Dalam, dan berbatasan langsung dengan masyarakat umum. Setiap kampung diambil 12 kk, kecuali di Kampung Kaduketug (ibu kota Desa Kanekes / Pusat pemerintahan) 14 orang, sehingga seluruh sampel adalah 182 orang KK. Cara mengambilnya dengan memperhatikan posisi rumah, mengingat rumah orang Baduy saling berhadapan selalu ke arah Utara dan ke arah Selatan, diambil masing-masing 6 kepala keluarga dengan menghitung 1 interval tiap rumah terpilih. Sebutan jalur masuk untuk seterusnya disebut lokasi penelitian.

Data primer dikumpulkan melalui daftar pertanyaan dengan skala Likert. Sumber data primer diperoleh langsung dari kepala kampung. Kuesioner digunakan sebagai pedoman wawancara dalam mengumpulkan data primer mengingat komunitas Baduy kebanyakan tidak bisa baca tulis, kecuali yang dapat membaca diminta untuk mengisi sendiri. Data skunder bersumber dari pustaka, rekaman, keterangan lisan dari pakar yang mengetahui tentang Orang Baduy Luar.

Data faktor individu, dianalisis dengan menggunakan distribusi frekuensi, hubungan antara peubah yang memnbentuk persepsi KK pada kebutuhan keluarga dianalisis dengan menggunakan koefisien korelasi product moment, dan analisis regresi perhitungan ini untuk menguji keeratan hubungan variabel-variabel dalam hipotesis.

\section{Hasil dan Pembahasan}

\section{Deskripsi Interaksi Sosial}

Karakteristik interaksi kepala keluarga Baduy Luar adalah interaksi yang dilakukan dalam kehidupan sehari-hari terutama menyangkut masalah kegiatan pemenuhan kebutuhan keluarga, yang menjadi fokus perhatian interaksi sosial disini adalah komunikasi interpersonal antar sesama kepala keluarga Baduy Luar, media komunikasi, dan interaksi dengan agen pembaharu. Data setiap lokasi seperti pada Tabel 1.

\section{Interaksi Sosial}

Interaksi Sosial di lokasi Bawah Barat (a) sebagian besar KK (61.1\%) meyatakan sering melakukan berdiskusi atau berkomunikasi interpersonal. Dalam memanfaatkan media sebagian KK $(50.0 \%)$ cenderung menyatakan kadang-kadang memanfaatkan media. Berinteraksi dengan agen pembaharu paling banyak (54.2\%) menyatakan kadang-kadang berinteraksi. Di lokasi Tengah Barat (b) sebagian besar KK (72.9\%) menyatakan sering mereka melakukan berdiskusi dengan sesamanya. Sebagian besar KK $(42.7 \%)$ menyatakan sering memanfaatkan media. Dengan para agen pembaharu paling banyak $(70.8 \%)$ adalah sering. Dan lokasi Kaduketug (c) paling banyak KK (50.0\%) menyatakan kadang-kadang mereka lakukan 
berdiskusi Memanfaatkan media sebagian kk (57.1\%) menyatakan kadang-kadang. dan interaksi dengan para agen pembaharu paling banyak $(78.6 \%)$ menyatakan atau kadang-kadang mereka berinteraksi. Dari deskripsi untuk setiap jalur dapat dikemukakan ada perbedaan mengenai komunikasi interpersonal atau diskusi diantara KK untuk Jalur Bawah Barat, Tengah Barat, dan Kaduketug.

Tabel 1. Interaksi Sosial Kepala Keluarga Berdasarkan Jalur Masuk ke Baduy Dalam

\begin{tabular}{lllrrrrrr}
\hline \multirow{2}{*}{ No } & $\begin{array}{l}\text { Interaksi } \\
\text { Sosial }\end{array}$ & Dimensi & \multicolumn{2}{c}{$\begin{array}{c}\text { Lokasi a } \\
\text { (Bawah Barat) } \\
\text { n= 72 }\end{array}$} & \multicolumn{2}{c}{$\begin{array}{c}\text { Lokasi b } \\
\text { (Tengah Barat) } \\
\text { n= 96 }\end{array}$} & \multicolumn{2}{c}{$\begin{array}{c}\text { Lokasi c } \\
\text { Kaduketug) } \\
\text { n= 14 }\end{array}$} \\
\cline { 3 - 9 } & & Jumlah & \% & Jumlah & \% & Jumlah & \% \\
\hline 1 & Komunikasi & Tinggi & 44 & 61.1 & 70 & 72.9 & 2 & 14.3 \\
& Interpersonal & Sedang & 25 & 34.7 & 22 & 22.9 & 8 & 57.1 \\
& & Rendah & 3 & 4.2 & 4 & 4.2 & 4 & 28.6 \\
& & Total & 72 & 100 & 96 & 100 & 14 & 100 \\
2 & Penggunaan & Tinggi & 24 & 33.3 & 41 & 42.7 & 6 & 42.9 \\
& Media & Sedang & 36 & 50.0 & 36 & 37.5 & 7 & 50.0 \\
& & Rendah & 12 & 16.7 & 19 & 19.8 & 1 & 7.1 \\
& & Total & 72 & 100 & 96 & 100 & 14 & 100 \\
3 & Agen & Tinggi & 25 & 34.7 & 68 & 70.8 & 3 & 21.4 \\
& Pembaharu & Sedang & 39 & 54.2 & 16 & 16.7 & 11 & 78.6 \\
& & Rendah & 8 & 11.1 & 12 & 12.5 & 0 & 0 \\
& & Total & 72 & 100 & 96 & 100 & 14 & 100 \\
\hline
\end{tabular}

\section{Persepsi terhadap Kebutuhan Keluarga yang Dirasakan}

Seperti dalam Tabel 2, persepsi terhadap kebutuhan fisiologi yang dirasakan di lokasi (a) paling banyak KK (58,3 persen) adalah tinggi, persepsi terhadap kebutuhan rasa aman paling banyak (73,6 persen) adalah tinggi, persepsi terhadap kebutuhan dicintai dan dimiliki paling banyak (70,8 persen) adalah tinggi. Persepsi terhadap kebutuhan dihargai paling banyak $(79,2$ persen) adalah tinggi.

Persepsi terhadap kebutuhan fisiologi yang dirasakan di lokasi (b) sebagian besar KK( 69,8 persen) adalah tinggi yaitu, persepsi terhadap kebutuhan rasa aman hampir seluruh (91,7 persen) adalah tinggi, persepsi terhadap kebutuhan dicintai dan dimiliki sebagian besar (70,3 persen) adalah tinggi, dan persepsi terhadap kebutuhan dihargai hampir seluruh kk $(93,7$ persen) adalah tinggi.

Persepsi terhadap kebutuhan fisiologi yang dirasakan di lokasi (c) sebagian besar KK (71,4 persen) adalah sedang, persepsi terhadap kebutuhan rasa aman sebagian (50,0 persen) adalah sedang, persepsi terhadap kebutuhan dicintai dan dimliki keluarga sebagian besar $(78,6$ persen) adalah sedang, dan persepsi terhadap kebutuhan dihargai sebagian besar ( 71,4 persen) adalah sedang.

Dari deskripsi masing-masing lokasi dapat disimpulkan di dua lokasi yaitu bawah barat (a), tengah barat (b) untuk kebutuhan dasar cenderung persepsinya sama yaitu tinggi, sedangkan lokasi Kaduketug cenderung persepsinya sedang. Untuk kebutuhan rasa aman juga demikian kedua jalur cenderung persepsinya sama yaitu tinggi, sedangkan Kaduketug cenderung persepsinya sedang. Kebutuhan dicintai dan dimiliki kedua lokasi a dan b, cenderung persepsinya sama yaitu tinggi, sedangkan Kaduketug persepsinya sedang. Dan kebutuhan dihargai baik a dan $b$ kedua lokasi cenderung persepsinya sama yaitu tinggi, sedangkan Kaduketug cenderung persepsinya sedang. 
Tabel 2. Persepsi Kepala Keluarga Terhadap Kebutuhan Keluarga yang dirasakan Berdasarkan Jalur Masuk ke Baduy Dalam

\begin{tabular}{|c|c|c|c|c|c|c|c|c|}
\hline \multirow[t]{2}{*}{ No } & \multirow{2}{*}{$\begin{array}{l}\text { Persepsi } \\
\text { Kepala } \\
\text { Keluarga } \\
\text { terhadap } \\
\text { kebutuhan }\end{array}$} & \multirow[t]{2}{*}{ Kategori } & \multicolumn{2}{|c|}{$\begin{array}{c}\text { Lokasi a } \\
\text { (Bawah Barat) } \\
\mathbf{n}=72\end{array}$} & \multicolumn{2}{|c|}{$\begin{array}{c}\text { Lokasi b } \\
\text { (Tengah Barat) } \\
\text { n=96 }\end{array}$} & \multicolumn{2}{|c|}{$\begin{array}{c}\text { Lokasi c } \\
\text { (Kaduketug) } \\
\mathbf{n}=\mathbf{1 4}\end{array}$} \\
\hline & & & Jumlah & $\%$ & Jumlah & $\%$ & Jumlah & $\%$ \\
\hline \multirow[t]{4}{*}{1} & \multirow[t]{4}{*}{ Fisiologi } & Tinggi & 42 & 58.3 & 67 & 69.8 & 1 & 7.2 \\
\hline & & Sedang & 28 & 38.9 & 23 & 23.9 & 10 & 71.4 \\
\hline & & Rendah & 2 & 2.8 & 6 & 6.3 & 3 & 21.4 \\
\hline & & Total & 72 & 100 & 96 & 100 & 14 & 100 \\
\hline \multirow[t]{4}{*}{2} & \multirow[t]{4}{*}{ Rasa aman } & Tinggi & 53 & 73.6 & 88 & 91.7 & 2 & 14.3 \\
\hline & & Sedang & 18 & 25.0 & 6 & 6.2 & 7 & 50.0 \\
\hline & & Rendah & 1 & 1.4 & 2 & 2.1 & 5 & 35.7 \\
\hline & & Total & 72 & 100 & 96 & 100 & 14 & 100 \\
\hline \multirow[t]{4}{*}{3} & \multirow{4}{*}{$\begin{array}{l}\text { Dicintai dan } \\
\text { dimiliki }\end{array}$} & Tinggi & 51 & 70.8 & 68 & 70.3 & 1 & 7.1 \\
\hline & & Sedang & 21 & 29.2 & 26 & 27.1 & 11 & 78.6 \\
\hline & & Rendah & 0 & 0 & 2 & 2.7 & 2 & 14.3 \\
\hline & & Total & 72 & 100 & 96 & 100 & 14 & 100 \\
\hline \multirow[t]{4}{*}{4} & \multirow[t]{4}{*}{ Dihargai } & Tinggi & 57 & 79.2 & 90 & 93.7 & 3 & 21.4 \\
\hline & & Sedang & 13 & 18.1 & 6 & 16.3 & 10 & 71.4 \\
\hline & & Rendah & 2 & 2.7 & 0 & 0 & 1 & 7.2 \\
\hline & & Total & 72 & 100 & 96 & 100 & 14 & 100 \\
\hline
\end{tabular}

Menurut Mulyanto dkk, (2006), orang Baduy menganggap hidup harus dijalani dengan sederhana, semampunya, dan sewajarnya. Pertama, hidup adalah untuk mencari kebahagian, bukan untuk mengejar materi. Kedua, tercukupi kebutuhan fisik; makan cukup, pakaian ada, dan bisa berbakti kepada orang tua. Ketiga, untuk mencari bahagia maka harus jujur, benar, dan pintar. Pintar saja tapi tidak benar, hal itu tidak indah. oleh karenanya jangan ada syirik, licik, jangan memfitnah, jangan berbohong, jangan selingkuh.

\section{Persepsi Kepuasan KK pada Kebutuhan Keluarga}

Tabel 3 menunjukkan, persepsi Kepuasan KK di lokasi a terhadap kebutuhan fisiologi seluruhnya (100 persen) adalah tinggi atau puas. Untuk kebutuhan rasa aman sebanyak 62,5 persen kk persepinya adalah tinggi, untuk kebutuhan dicintai dan dimiliki sebagian besar kk (62,50 persen) persepsinya adalah tinggi, dan kebutuhan dihargai paling banyak (59,7 persen) kk mempersepsi kepuasannya tinggi.

Persepsi Kepuasan KK di lokasi b terhadap kebutuhan fisiologi seluruh kk (100 persen) persepinya adalah tinggi, persepsi kepuasan KK terhadap kebutuhan rasa aman sebagian besar (88,5 persen) adalah tinggi, terhadap kebutuhan dicintai dan dimiliki keluarga paling banyak (88,5 persen) kk persepsiya adalah tinggi, dan terhadap kebutuhan dihargai hampir seluruh KK (93,7 persen) persepsinya adalah tinggi.

Persepsi Kepuasan KK di lokasi c terhadap kebutuhan fisiologi sebagian besar KK (78,6 persen) adalah tinggi. Untuk kebutuhan rasa aman Sebagian kk (57,1 persen) persepinya adalah rendah. Kebutuhan dicintai dan dimiliki hampir seluruh kk (92,9 persen) persepsinya adalah sedang, dan kebutuhan dihargai sebagian kk (50,0 persen) persepsinya adalah sedang. 
Tabel 3. Persepsi pada Kepuasan Kebutuhan Keluarga Berdasarkan Jalur Masuk ke Baduy Dalam

\begin{tabular}{|c|c|c|c|c|c|c|c|c|}
\hline \multirow[t]{2}{*}{ No } & \multirow{2}{*}{$\begin{array}{l}\text { Persepsi } \\
\text { Kepala } \\
\text { Keluarga } \\
\text { terhadap } \\
\text { kebutuhan } \\
\end{array}$} & \multirow[t]{2}{*}{ Kategori } & \multicolumn{2}{|c|}{$\begin{array}{c}\text { Lokasi a } \\
\text { (Bawah Barat) } \\
\text { n= 72 }\end{array}$} & \multicolumn{2}{|c|}{$\begin{array}{c}\text { Lokasi b } \\
\text { (Tengah Barat) } \\
\text { n =96 }\end{array}$} & \multicolumn{2}{|c|}{$\begin{array}{c}\text { Lokasi c } \\
\text { (Kaduketug) } \\
\mathbf{n}=\mathbf{1 4}\end{array}$} \\
\hline & & & Jumlah & $\%$ & Jumlah & $\%$ & Jumlah & $\%$ \\
\hline \multirow[t]{4}{*}{1} & Fisiologi & Tinggi & 72 & 100 & 96 & 100 & 11 & 78,6 \\
\hline & & Sedang & 0 & 0 & 0 & 0 & 2 & 14,3 \\
\hline & & Rendah & 0 & 0 & 0 & 0 & 1 & 7,1 \\
\hline & & Total & 72 & 100 & 96 & 100 & 14 & 100 \\
\hline \multirow[t]{4}{*}{2} & Rasa aman & Tinggi & 45 & 62,5 & 85 & 88,5 & 1 & 7,1 \\
\hline & & Sedang & 13 & 18,1 & 10 & 10,4 & 5 & 35,8 \\
\hline & & Rendah & 14 & 19,4 & 1 & 1,1 & 8 & 57,1 \\
\hline & & Total & 72 & 100 & 96 & 100 & 14 & 100 \\
\hline \multirow[t]{4}{*}{3} & Dicintai dan & Tinggi & 45 & 62,5 & 85 & 88,5 & 1 & 7,1 \\
\hline & dimiliki & Sedang & 26 & 36,1 & 8 & 8,3 & 13 & 92,9 \\
\hline & & Rendah & 1 & 1,4 & 3 & 3,2 & 0 & 0 \\
\hline & & Total & 72 & 100 & 96 & 100 & 14 & 100 \\
\hline \multirow[t]{4}{*}{4} & Dihargai & Tinggi & 43 & 59,7 & 90 & 93,7 & 1 & 7,1 \\
\hline & & Sedang & 16 & 22,2 & 4 & 4,2 & 7 & 50,0 \\
\hline & & Rendah & 13 & 18,1 & 2 & 2,1 & 6 & 42,9 \\
\hline & & Total & 72 & 100 & 96 & 100 & 14 & 100 \\
\hline
\end{tabular}

Dari hasil analisis tersebut dapat disimpulkan, hampir seluruh KK di setiap jalur persepsinya tinggi terhadap kepuasannya pada kebutuhan dasar. KK yang kepuasan keamanannya kurang terpenuhi hanya pada KK di Kaduketug. Persepsi kepuasan kebutuhan dicintai dan dimiliki KK pada jalur Bawah Barat dan Tengah Barat cenderung kepuasannya tinggi, di Kaduketug kepuasannya sedang. Ada kecenderungan hampir seluruh KK merasa persepsinya puas pada kebutuhan dihargai. Artinya, yang mereka peroleh dan terima saat ini baik pakaian, rumah, dan makanan dianggap sudah memadai. Dari pengamatan peneliti kaitannya dengan kebutuhan fisiologi terlihat bahwa kesederhanaan dan kebersamaan dalam kelompok sangat terlihat baik dalam penampilan (berpakaian), rumah, dan makanan yang dikonsumsinya.

\section{Hubungan Antara Interaksi Sosial dengan Persepsi pada Kebutuhan Keluarga yang Dirasakan}

Hasil uji korelasi di lokasi Bawah Barat menunjukkan terdapat hubungan yang nyata (positif) antara Interaksi sosial melalui; kegiatan komunikasi interpersonal terdapat hubungan yang nyata postif dengan; kebutuhan dasar $(r=0,362)$, kebutuhan rasa aman $(r=0,425)$, kebutuhan dicintai $(r=0,371)$, dan kebutuhan dihargai keluarga/kelompok, $(r=0,483)$; pemanfaatan media massa terdapat hubungan yang nyata postif dengan; kebutuhan dasar ( $\mathrm{r}=$ $0,049)$, kebutuhan rasa aman $(\mathrm{r}=0,056)$, kebutuhan dicintai $(\mathrm{r}=0,111)$, dan kebutuhan dihargai keluarga dan kelompok, $(\mathrm{r}=0,284)$;

Antara agen pembaharu terdapat hubungan yang nyata postif dengan; kebutuhan dasar $(\mathrm{r}=0,341)$, kebutuhan rasa aman $(\mathrm{r}=0,445)$, kebutuhan dicintai $(\mathrm{r}=0,480)$, dan kebutuhan dihargai keluarga dan kelompok, $(\mathrm{r}=0,451)$; termasuk hubungan yang cukup kuat.

Interaksi sosial melalui di lokasi Tengah Barat; kegiatan komunikasi interpersonal terdapat hubungan yang nyata postif dengan persepsi yang dirasakan pada; kebutuhan dasar ( $\mathrm{r}=$ $0,362)$, kebutuhan rasa aman $(\mathrm{r}=0,097)$, kebutuhan dicintai $(\mathrm{r}=0,363)$, dan kebutuhan dihargai keluarga/kelompok, $(\mathrm{r}=0,483)$. Artinya bila interaksi diskusi meningkat maka persepi yang 
diarasakan baik pada kebuituhan keluarga, meskipun hubungannya lemah, kecuali pada kebutuhan dihargai dan dicintai cukup kuat.

Antara media massa terdapat hubungan yang nyata postif dengan persepsi yang dirasakan pada; kebutuhan dasar $(\mathrm{r}=0,162)$, kebutuhan rasa aman $(\mathrm{r}=0,086)$, kebutuhan dicintai $(\mathrm{r}=0,051)$, dan kebutuhan dihargai keluarga dan kelompok, $(\mathrm{r}=0,308)$; Artinya bila interaksi dengan media meningkat maka persepi yang diarasakan baik pada kebuituhan keluarga, meskipun hubungannya sangat lemah, kecuali pada kebutuhan dihargai kelompok dan keluarga cukup kuat.

Tabel 4. Hubungan antara Interaksi Sosial dengan Persepsi

\begin{tabular}{|c|c|c|c|c|c|}
\hline \multirow[b]{2}{*}{ No } & \multirow[b]{2}{*}{ Variabel } & \multicolumn{4}{|c|}{ Persepsi terhadap Kebutuhan yang dirasakan } \\
\hline & & $\begin{array}{l}\text { Kebutuhan } \\
\text { dasar } \\
(\mathrm{Y} 1.1)\end{array}$ & $\begin{array}{c}\text { Kebutuhan Rasa } \\
\text { Aman (Y1.2) }\end{array}$ & $\begin{array}{l}\text { Kebutuhan } \\
\text { dicintai } \\
\text { (Y1.3) }\end{array}$ & $\begin{array}{l}\text { Kebutuhan } \\
\text { dihargai } \\
\text { (Y1.4) } \\
\end{array}$ \\
\hline \multirow{5}{*}{1.} & Lokasi Bawah Barat & & & & \\
\hline & Komunikasi & $0,362 * *$ & $0,425 * *$ & $0,371 * *$ & $0,483 * *$ \\
\hline & Interpersonal (X4.1) & & & & \\
\hline & Media $(\mathrm{X} 4.2)$ & 0,049 & 0,056 & 0,111 & $0,284 * *$ \\
\hline & $\begin{array}{l}\text { Agen Pembaharu } \\
\text { (X4.3) }\end{array}$ & $0,341 * *$ & $0,445^{* *}$ & $0,480 * *$ & $0,451 * *$ \\
\hline \multirow[t]{5}{*}{2} & Lokasi Tengah Barat & & & & \\
\hline & Komunikasi & 0,130 & 0,097 & $0,363 * *$ & $0,483 * *$ \\
\hline & Interpersonal (X4.1) & & & & \\
\hline & Media (X4.2) & 0,162 & 0,086 & 0,051 & $0,308 * *$ \\
\hline & $\begin{array}{ll}\text { Agen } & \text { Pembaharu } \\
(\mathrm{X} 4.3) & \\
\end{array}$ & $-0,164 * *$ & $-0,047$ & $0,337 * *$ & $0,214^{*}$ \\
\hline \multirow[t]{5}{*}{3} & Lokasi Kaduketug & & & & \\
\hline & Komunikasi & 0,372 & 0,427 & 0,210 & 0,062 \\
\hline & Interpersonal (X4.1) & & & & \\
\hline & Media (X4.2) & $-0,519$ & 0,186 & $-0,165$ & 0,065 \\
\hline & $\begin{array}{l}\text { Agen Pembaharu } \\
(\mathrm{X} 4.3)\end{array}$ & 0,145 & 0,166 & 0,082 & $-0,483$ \\
\hline Kete & $\begin{array}{r}\text { angan: } * * \text { taraf nyata } 0,0 \\
\text { Pedoman interpr } \\
0,0-0,20 \text { hubun } \\
0,1-0,60 \text { hubun }\end{array}$ & $\begin{array}{l}* \text { taraf nyata } \\
\text { asi koefisien } \mathrm{k} \\
\text { an sangat lema } \\
\text { an cukup kuat }\end{array}$ & $\begin{array}{l}, 05 . \\
\text { relasi sbb: } \\
; 0,21-0,40 \text { hub } \\
0,61-0,80 \text { hubun }\end{array}$ & $\begin{array}{l}\text { gan lemah; } \\
\text { kuat; }\end{array}$ & \\
\hline
\end{tabular}

Interaksi dengan agen pembaharu terdapat hubungan yang nyata postif dengan; kebutuhan dicintai $(\mathrm{r}=0.337)$, kebutuhan dihargai keluarga dan kelompok kebutuhan rasa aman $(r=0.214)$. Artinya bila interaksi dengan agen pembaharu meningkat maka persepi yang diarasakan baik pada kebutuhan dihargai keluarga, dan dicintai meskipun hubungannya lemah. Sedangkan korelasi dengan kebutuhan dasar dan rasa aman negatif.

Interaksi sosial melalui di lokasi Kaduketug; kegiatan komunikasi interpersonal terdapat hubungan yang nyata postif dengan persepsi yang dirasakan pada; kebutuhan dasar $(r=0.372)$, kebutuhan rasa aman $(\mathrm{r}=0.427)$, kebutuhan dicintai $(\mathrm{r}=0.210)$, kebutuhan dihargai keluarga/kelompok, $(r=0,062)$. Hubungannya cukup kuat, kecuali pada kebutuhan dihargai sangat lemah.

Antara media massa dengan kebutuhan keluarga terdapat hubungan yang nyata positif namun lemah dan negatif dengan persepsi yang dirasakan pada; kebutuhan dasar $(\mathrm{r}=-0.519)$, kebutuhan rasa aman $(r=0.186)$, kebutuhan dicintai $(r=-0.165)$, dan kebutuhan dihargai keluarga dan kelompok, $(\mathrm{r}=0,065)$; Artinya bila interaksi dengan media meningkat maka persepi yang diarasakan baik pada kebutuhan keluarga, meskipun hubungannya sangat lemah, kecuali pada kebutuhan dasar dan kebutuhan dicintai negatif. 
Interaksi dengan agen pembaharu juga terdapat hubungan yang nyata postif tetapi lemah, dan ada juga hubungan negatif dengan persepsi yang dirasakan pada; kebutuhan dasar $(\mathrm{r}=0,145)$, kebutuhan rasa aman $(\mathrm{r}=0,166)$, kebutuhan dicintai $(\mathrm{r}=0,086)$, Artinya bila interaksi dengan agen pembaharu meningkat maka persepi yang diarasakan baik pada kebutuhan dasar, rasa aman, dan dicintai meskipun sangat lemah. Sedangkan korelasi dengan kebutuhan dihargai negatif.

Dari uraian di atas di setiap lokasi Jalur hubungan yang nyata dan kuat adalah interaksi kk dengan melalui komunikasi interpersonal yaitu berdiskusi diantara sesama kk, dan interaksi dengan agen pembaharu.

\section{Hubungan Antara Interaksi Sosial dengan Persepsi pada Kepuasan Kebutuhan Keluarga yang Dirasakan}

Interaksi sosial di lokasi Bawah Barat melalui; kegiatan komunikasi interpersonal terdapat hubungan yang nyata postif dengan persepsi kepuasan kk pada; kebutuhan dasar $(\mathrm{r}=$ $0,135)$, kebutuhan rasa aman $(\mathrm{r}=0,497)$, kebutuhan dicintai $(\mathrm{r}=0,468)$, dan kebutuhan dihargai keluarga / kelompok, $(\mathrm{r}=0,559)$; antara media massa terdapat hubungan yang nyata postif dengan persepsi kepuasan kk pada; kebutuhan rasa aman $(\mathrm{r}=0,021)$, kebutuhan dicintai $(\mathrm{r}=$ $0,183)$, dan kebutuhan dihargai keluarga dan kelompok, $(\mathrm{r}=0,234)$; sedangkan dengan kebutuhan dasar negatif $(r=-0,206)$. Antara agen pembaharu terdapat hubungan yang nyata positif dengan persepsi kepuasan kk pada kebutuhan; kebutuhan rasa aman $(r=0,404)$, kebutuhan dicintai $(\mathrm{r}=0,451)$, dan kebutuhan dihargai keluarga dan kelompok, $\quad(\mathrm{r}=0,505)$; termasuk hubungan yang cukup kuat.

Interaksi sosial di lokasi Tengah Barat melalui; kegiatan komunikasi interpersonal terdapat hubungan yang nyata positif dengan persepsi kepuasan kk pada kebutuhan; kebutuhan dasar $(r=0,278)$, kebutuhan rasa aman $(r=0,160)$, kebutuhan dicintai $(r=0,250)$, dan kebutuhan dihargai keluarga/kelompok hubungannya negatif, $(r=-0,119)$. Interaksi dengan media terdapat hubungan nyata positif dengan persepsi kepuasan kk pada; kebutuhan dasar $(r=0,105)$, kebutuhan dicintai $(r=0,194)$, dan kebutuhan dihargai keluarga dan kelompok. Artinya semakin baik interaksinya dengan media radio, tv, koran, maka semakin baik persepsinya pada kebutuhan dasar, dicintai, dan dihargai meskipun hubungannya sangat lemah. Hubungan dengan rasa aman negatif.

Antara agen pembaharu terdapat hubungan yang nyata postif dengan persepsi kepuasan kk pada kebutuhan; kebutuhan rasa aman $(r=0,117)$, kebutuhan dicintai $(r=0,029)$. Dengan demikian semakin baik interaksi melalui komunikasi interpersonal, dengan media (radio, televisi, suratkabar), dan dengan agen pembaharu (manteri kesehatan, guru, bidan, carik desa, wisatawan) yang dilakukan, maka persepsi kepuasan kk pada kebutuhan keluarga baik rasa aman, dicintai dan dimiliki, dan dihargai keluarga dan kelompok baik, tetapi hubungannya sangat lemah.

Kepuasan yang nyata dan lebih dari yang lain di lokasi Tengah Barat adalah interaksi antara kk dengan melalui komunikasi interpersonal yaitu berdiskusi di antara sesama kk dengan kebutuhan dasar, tetapi hubungannya sangat lemah. Hasil analisis untuk peubah interaksi umumnya hubungan yang terjadi sangat lemah.

Interaksi sosial di Kaduketug melalui; kegiatan komunikasi interpersonal terdapat hubungan yang nyata positif dengan persepsi kepuasan kk pada kebutuhan; kebutuhan rasa aman $(r=0,535)$ korelasinya cukup kuat. Korelasi dengan kebutuhan dasar negatif. Dengan kebutuhan dicintai dan kebutuhan dihargai keluarga/kelompok cenderung sangat lemah.

Antara media massa terdapat hubungan yang nyata postif dengan persepsi kepuasan kk pada kebutuhan; kebutuhan dasar $(\mathrm{r}=0,681)$, kebutuhan rasa aman $(\mathrm{r}=0,467)$ korelasinya kuat. Dengan kebutuhan dicintai korelasinya negatif dan dengan kebutuhan dihargai keluarga dan kelompok korelasinya lemah. Antara agen pembaharu terdapat hubungan yang nyata postif dengan persepsi kepuasan kk pada kebutuhan; kebutuhan dicintai $(r=0,531)$ korelasinya kuat. Korelasi dengan kebutuhan dasar, rasa aman, dan dihargai lemah. 
Tabel 5. Hubungan antara Interaksi Sosial dengan Persepsi

\begin{tabular}{|c|c|c|c|c|c|}
\hline \multirow[b]{2}{*}{ No } & \multirow[b]{2}{*}{ Variabel } & \multicolumn{4}{|c|}{ Persepsi terhadap kepuasan Kebutuhan } \\
\hline & & $\begin{array}{l}\text { Kebutuhan } \\
\text { dasar } \\
\text { (Y2.1) }\end{array}$ & $\begin{array}{l}\text { Kebutuhan } \\
\text { Rasa Aman } \\
\text { (Y2.2) }\end{array}$ & $\begin{array}{l}\text { Kebutuhan } \\
\text { dicintai } \\
\text { (Y2.3) }\end{array}$ & $\begin{array}{l}\text { Kebutuhan } \\
\text { dihargai } \\
\text { (Y2.4) }\end{array}$ \\
\hline 1 & $\begin{array}{l}\text { Lokasi Bawah Barat } \\
\text { Komunikasi } \\
\text { Interpersonal (X4.1) }\end{array}$ & 0,135 & $0,497 * *$ & $0,468 * *$ & $0,559 * *$ \\
\hline & Media (X4.2) & $-0,206$ & 0,021 & 0,183 & $0,234 *$ \\
\hline & $\begin{array}{l}\text { Agen Pembaharu } \\
\text { (X4.3) }\end{array}$ & $-0,005 * *$ & $0,404 * *$ & $0,451 * *$ & $0,505 * *$ \\
\hline 2 & $\begin{array}{l}\text { Lokasi Tengah Barat } \\
\text { Komunikasi } \\
\text { Interpersonal (X4.1) }\end{array}$ & 0,130 & 0,097 & $0,363 * *$ & $0,483 * *$ \\
\hline & Media (X4.2) & 0,162 & 0,086 & 0,051 & $0,308 * *$ \\
\hline & $\begin{array}{ll}\text { Agen } & \text { Pembaharu } \\
(\mathrm{X} 4.3) & \end{array}$ & $-0,164 * *$ & $-0,047$ & $0,337 * *$ & $0,214 *$ \\
\hline & $\begin{array}{l}\text { Lokasi Kaduketug } \\
\text { Komunikasi } \\
\text { Interpersonal (X4.1) }\end{array}$ & $-0,108$ & $0,535^{*}$ & 0,062 & $-0,131$ \\
\hline & Media (X4.2) & $0,681^{* *}$ & 0,467 & $-0,162$ & 0,342 \\
\hline & $\begin{array}{l}\text { Agen Pembaharu } \\
\text { (X4.3) }\end{array}$ & 0,253 & 0,139 & 0,531 & 0,306 \\
\hline
\end{tabular}

Keterangan: ** taraf nyata 0,$01 ; *$ taraf nyata 0,05 .

Pedoman interpretasi koefisien korelasi sbb:

$0,0-0,20$ hubungan sangat lemah ; $0,21-0,40$ hubungan lemah;

$0,1-0,60$ hubungan cukup kuat; $0,61-0,80$ hubungan kuat;

Dengan demikian semakin baik interaksi melalui komunikasi interpersonal, dengan media, dan dengan agen pembaharu yang dilakukan, maka persepsi kepuasan kk pada kebutuhan keluarga baik kebutuhan dasar, rasa aman, dan dicintai baik.

Meskipun demikian di Jalur Kaduketug kepuasan yang nyata dan lebih dari yang lain adalah interaksi antara kk dengan media yaitu memanfaatkan media massa, berdiskusi diantara sesama kk degan kebutuhan dasar juga cukup kuat. Di Jalur Kaduketug akses media lebih baik karena berbatasan dengan desa-desa lain, dan sebagai gerbang atau pintu masuk ke perkampungan Baduy.

\section{Kesimpulan}

Persepsi KK Komunitas Adat Baduy Luar di lokasi Bawah Barat dan Tengah Barat pada kebutuhan keluarga: Kebutuhan fisiologi, rasa aman, dicintai dan dimiliki, dan dihargai kelompok adalah tinggi; di lokasi Kaduketug pada kebutuhan tersebut adalah sedang.

Kepuasan KK Komunitas Adat Baduy Luar di jalur Bawah Barat dan Tengah Barat pada kebutuhan keluarga: Kebutuhan fisiologi, rasa aman, dicintai dan dimiliki, dan dihargai kelompok adalah tinggi. Di lokasi Kadukteug kepuasan pada kebutuhan fisiologi adalah tinggi, rasa aman rendah, dicintai dan dimiliki sedang, dihargai adalah sedang.

Interaksi sosial melalui komunikasi interpersonal dan dengan agen pembaharu berhubungan nyata dengan persepsi KK pada kebutuhan dasar, kebutuhan rasa aman, kebutuhan dicintai, dan kebutuhan dihargai yang dirasakannya, dan persepsi pada kepuasan kebutuhan dasar rasa aman, kebutuhan dicintai, dan dihargai. 


\section{Daftar Pustaka}

Abdullah, Natsir., 2004. Penanganan Komunitas Adat Terpencil Di Indonesia Metode Dan Pendekatan. Prosiding Seminar Pengembangan Kawasan Tertinggal Berbasis Komunitas Adat Terpencil. Jakarta. Direktorat Pengembangan Kawasan Khusus dan Tertinggal BAPPENAS.

Adimihardja, Kusnaka., 2007. Dinamika Budaya Lokal. Bandung. CV. Indra Prahasta dan Pusat Kajian LBPB.

Alwisol. 2004. Psikologi Kepribadian. Malang. Universitas Muhamadiyah Malang Press.

Anonimous. 1999. Keppres No. 111/1999 Tentang Pembinaan Kesejahteraan Sosial Komunitas Adat Terpencil. Jakarta. Direktorat Pembinaan Komunitas Adat Terpencil. Departemen Sosial RI.

Anonimous. 2001. Perda No. 32 Tahun 2001 tentang Perlindungan atas Hak Ulayat Masyarakat Baduy.

Asngari, Pang. S., 1984. "Persepsi Direktur Penyuluhan Tingkat "Karesidenan" dan Kepala Penyuluh Pertanian Terhadap Peranan dan Fungsi Lembaga Penyuluhan Pertanian Di Negara Bagian Texas Amerika Serikat.” Media Peternakan Tahun 1984. Volume 9. No.2. Bogor. Fakultas Peternakan. Institut Pertanian Bogor.

Beaver, I. 1962. Iowa County Extention Committee Members and Agent Perception of Program Planning. Dissertation Abstracts. Wisconsin University.

Garna, Judistira, K., 1993a. Masyarakat Baduy di Banten., dalam Koentjaraningrat (ed) Masyarakat Terasing di Indonesia. Jakarta. Depsos RI, Dewan Nasional Indonesia untuk Kesejahteraan Sosial, dan Gramedia. .2007., Sistim Budaya Indonesia. Bandung. The Judistira Garna Foundation dan Primaco Akademika.

Iskandar, Johan., 1992. Ekologi Perladangan di Indonesia. Studi Kasus Dari Daerah Baduy Banten Selatan, Jawa Barat. Jakarta. Penerbit Djambatan.

Kusdinar, Aan., 2004. Kebijakan Pemerintah Kabupaten Lebak dalam Penanganan Komunitas Adat Terpencil Baduy. Prosiding Seminar Pengembangan Kawasan Tertinggal Berbasis Komunitas Adat Terpencil. Jakarta. Direktorat Pengembangan Kawasan Khusus dan Tertinggal BAPPENAS.

Kolopaking, Lala. M. et.al. (editor). Sosiologi Umum. Bagian Ilmu-Ilmu Sosial. Komunikasi dan Ekologi Manusia. Jurusan Sosek Faperta. IPB.

Mulyanto , Nanik Prihartanti, dan Moordiningsih. 2006. Perilaku Konformitas Masyarakat

Baduy http://eprints.ums.ac.id/650/1/1 Perilaku Konformitas-Baduy.doc., download, 19 januari 2009.

Permana, R. Cecep Eka. 2006. Tata Ruang Masyarakat Baduy. Jakarta. Wedata Widya Sastra.

Rakhmat, Jalaluddin. 2004. Psikologi Komunikasi. Bandung. PT. Remaja Rosdakarya. 